\title{
Links between low physical activity and vitamin $D$ deficiency on coronary artery disease in patients undergoing coronary angiography
}

\begin{abstract}
Low physical activity and vitamin D deficiency are two risk factors in public health burdens accounting for most coronary artery disease (CAD) morbidity and mortality worldwide. The prevalence of CAD is increasing in the both men and women. Since the effect of physical activity and vitamin D on number of involved vessels in patients undergoing coronary angiography are unknown, studies needs to be done to combat this public health scourge.
\end{abstract}

Keywords: Physical Activity, Vitamin D, Coronary Artery Disease
Volume II Issue 2 - 2018

\author{
Rastegar Hoseini,' Zahra Hoseini ${ }^{2}$ \\ 'Assistant Professor, Department of Exercise Physiology, Faculty \\ of Sport Sciences, Razi University, Iran \\ 2MSc student, Department of Exercise Physiology, Faculty of \\ Sport Sciences, Razi University, Iran
}

\author{
Correspondence: Rastegar Hoseini,Assistant Professor, \\ Department of Exercise Physiology, Faculty of Sport Sciences, \\ Razi University, Kermanshah, Iran, \\ Email rastegar.hoseini@gmail.com
}

Received: December 21, 2017 | Published: April 17, 2018

\section{Introduction}

Cardiac accidents due to coronary artery disease are the most common cause of mortality in the world. ${ }^{1,2}$ On the other hand, low physical activity and vitamin D deficiency are known as an emerging risk factor of this disease. ${ }^{3,4}$ Vitamin D deficiency is highly prevalent; approximately $25 \%-57 \%$ of the US population ${ }^{2}$ and more than 1 billion persons worldwide; ${ }^{5,6}$ Also, the benefits of physical activity in the prevention and treatment of CAD have been very well described in adults. ${ }^{6}$ Considering the high prevalence of decrease physical activity and vitamin D deficiency in Iran we investigated the prevalence of vitamin D deficiency in angioplasty patients, effect of physical activity and its relationship with coronary artery disease.

\section{Materials and methods}

In this cross-sectional study two-hundred patients undergoing coronary angiography (men; $n=100$ with mean age $45.3 \pm 6.3$ years and women; $\mathrm{n}=100$ with mean age $43.6 \pm 4.2$ years) were selected using the clustering method for sampling. Subjects completed an informed consent form, health history questionnaire and physical activity questionnaire (Baecke) and serum level of $25(\mathrm{OH}) \mathrm{D} 3$ was measured. Patients with renal failure $(\mathrm{Cr}>2 \mathrm{mg} / \mathrm{dl})$, liver disease, and those treated with glucocorticoids or anti-epileptic drugs were excluded. For data analysis, inferential statistics of Kolmogorov-Smirnov and Pearson correlation coefficient were used.

\section{Results}

Physical activity levels were low (men $62.4 \%$ and women $68.5 \%$ ) or insufficient (men 37.6\% and women 31.5\%); Also, prevalence of vitamin D deficiency was $82.3 \%$ (men $68.2 \%$ and women $81.5 \%$ ). Low physical activity level and vitamin $\mathrm{D}$ deficiency were related to the number of involved vessels in subjects $(\mathrm{r}=0.78, \mathrm{P}=0.001$ and $\mathrm{r}=0.65, \mathrm{P}=0.021$ respectively). The pattern effect of low physical activity and vitamin $\mathrm{D}$ deficiency on coronary artery disease seems not to be different in men and women.

\section{Conclusion}

Maintaining an optimal physical activity and vitamin D serum level seems important not only for calcium homeostasis but also for blood pressure control, prevalence of stroke, metabolic syndrome, peripheral artery disease and CAD. Observational data support the link between physical activity and vitamin $\mathrm{D}$ status and $\mathrm{CAD}$, and decrees physical activity and vitamin $\mathrm{D}$ deficiency can be considered a CAD risk marker. ${ }^{3,4}$ Physical activity and vitamin D exert their cardiovascular effects by reducing the activity of the reninangiotensin-aldosterone system, ${ }^{7}$ lowering blood pressure values, ${ }^{8}$ and having an antiinflammatory, ${ }^{9}$ antiproliferative, antihypertrophic and antithrombotic effect $^{10}$ and beneficial modulation of classical cardiovascular risk factors. The mentioned effects might be very important for public health, considering the high prevalence of vitamin D deficiency and low physical activity, the aging population, and the indoor oriented lifestyle. Complementary studies are needed to elucidate this issue further.

\section{References}

1. Bauters C, Tricot O, Meurice T, et al. Long-term risk and predictors of cardiovascular death in stable coronary artery disease: the CORONOR study. Coron Artery Dis. 2017;28(8):636-41.

2. Darke S, Duflou J, Kaye S. Prevalence and nature of cardiovascular disease in methamphetamine-related death: A national study. Drug Alcohol Depend. 2017;179:174-9.

3. Barrea L, Savastano S, Di Somma C, et al. Low serum vitamin D-status, air pollution and obesity: A dangerous liaison. Rev Endocr Metab Disord. 2017;18(2):207-214.

4. Aune D, Sen A, Leitzmann MF, et al. Body mass index and physical activity and the risk of diverticular disease: a systematic review and metaanalysis of prospective studies. Eur J Nutr. 2017;56(8):2423-2438.

5. Frigstad SO, Høivik M, Jahnsen J, et al. Vitamin D deficiency in inflammatory bowel disease: prevalence and predictors in a Norwegian outpatient population. Scand J Gastroenterol. 2017;52(1):100-6. 
6. Kondamudi N, Haykowsky M, Forman DE, et al. Exercise training for prevention and treatment of heart failure. Prog Cardiovasc Dis. 2017;60(1):115-20

7. McMullan CJ, Borgi L, Curhan GC, et al. The effect of vitamin D on renin-angiotensin system activation and blood pressure: a randomized control trial. J Hypertens. 2017;35(4):822-9.

8. van Ballegooijen AJ, Cepelis A, Visser M, et al. Joint Association of Low Vitamin D and Vitamin K Status With Blood Pressure and HypertensionNovelty and Significance. Hypertension. 2017;69(6):1165-72.
9. Walhovd KB, Storsve AB, Westlye LT, et al. Blood markers of fatty acids and vitamin $\mathrm{D}$, cardiovascular measures, body mass index, and physical activity relate to longitudinal cortical thinning in normal aging. Neurobiol Aging. 2014;35(5):1055-64.

10. Frey PM, Méan M, Limacher A, et al. Physical activity and risk of bleeding in elderly patients taking anticoagulants. $J$ Thromb Haemost. 2015;13(2):197-205. 